\title{
Fifth Pharyngeal Pouch
}

National Cancer Institute

\section{Source}

National Cancer Institute. Fifth Pharyngeal Pouch. NCI Thesaurus. Code C34174.

The area adjacent to the fourth pharyngeal pouch that forms the ultimobranchial body, and gives rise to parafollicular or $C$ cells of the thyroid gland. 